\title{
On the Role of the Wideband Inhibitor in the Dorsal Cochlear Nucleus: A Computational Modeling Study
}

\author{
Oleg Lomakin $^{1,2,3}$ and Kevin A. Davis ${ }^{1,2,3}$ \\ ${ }^{1}$ Department of Biomedical Engineering, University of Rochester, Rochester, NY 14642, USA \\ ${ }^{2}$ Department of Neurobiology and Anatomy, University of Rochester, 601 Elmwood Ave., Box 603 Rochester, NY 14642, USA \\ ${ }^{3}$ Center for Navigation and Communication Sciences, University of Rochester, Rochester, NY 14642, USA
}

Received: 19 November 2007; Accepted: 10 July 2008; Online publication: 14 August 2008

\begin{abstract}
Principal cells (type IV units) in the dorsal cochlear nucleus (DCN) are uniquely sensitive to (are inhibited by) energy minima or notches in acoustic spectra, which provide cues to sound localization. The once accepted conceptual model of the DCN suggested that this sensitivity was shaped largely by inhibitory inputs from wideband inhibitors (WBIs), which received auditory nerve inputs over a wide frequency range and inhibited type IV units over a narrow frequency range. A computational model based on this wide-input narrow-output conceptual model was able to reproduce quantitatively type IV unit responses to notch-noise stimuli as a function of notch width. Recent physiological results have shown however that WBIs are unresponsive to notch-noise stimuli with wide notch widths and thus have narrower auditory nerve fiber input bandwidths than previously assumed. A computational model based on a narrow-input narrow-output model of the WBI was unable to account fully for the notch sensitivity of type IV units suggesting the need to add a new component to the DCN circuit. The goal of this study was to test whether making the output bandwidth of the WBIs wide while keeping their input bandwidth narrow could explain the responses of type IV units to notchnoise stimuli. Anatomical evidence supports this model configuration, and the results show that such a model can produce strong inhibition in type IV units for wide notches. The results thus suggest that WBIs,
\end{abstract}

Correspondence to: Kevin A. Davis · Department of Neurobiology and Anatomy - University of Rochester · 601 Elmwood Ave., Box 603 Rochester, NY 14642, USA. Telephone: +1-585-2734844; fax: +1-5857565334; email: Kevin_Davis@urmc.rochester.edu in narrow-input wide-output form, are sufficient to account for the notch sensitivity of DCN type IV units.

Keywords: hearing, sound localization, spectral cues, notch noise, neural modeling

\section{INTRODUCTION}

The dorsal cochlear nucleus (DCN) is part of the first auditory structure in the brainstem. It receives input from the auditory nerve (Osen 1970; Ryugo and May 1993) and, in turn, projects to the inferior colliculus (Adams 1979; Osen 1972). Physiological studies in cats have shown that the principal cells of the DCN are especially sensitive to notches in acoustic spectra (Young et al. 1992; Imig et al. 2000), of the kind added to sounds in a direction-dependent manner by the external ear (Musicant et al. 1990; Rice et al. 1992). When tested with pure tones, DCN principal cells in cats exhibit type IV unit response properties. Type IV units are excited by low-level tones at their best frequency (BF) but are inhibited by high-level tones at nearly all frequencies (Young and Brownell 1976; Spirou and Young 1991). Despite the prevalence of inhibitory responses to tones, type IV units are excited by broadband noise. Inhibition is restored by adding a notch to the broadband spectrum at BF (Spirou and Young 1991; Nelken and Young 1994). This unusual sensitivity to notches suggests that the DCN is involved in early analysis of sound source location. Consistent with this interpretation, lesioning the output pathway of the DCN causes cats to display 
poorly directed sound orientation behaviors (Sutherland et al. 1998; May 2000).

The traditional conceptual model of the DCN (Fig. 1A; Nelken and Young 1994) suggests that type IV unit responses to sound are shaped by inputs from two inhibitory interneurons: type II units and wideband inhibitors (WBIs). Type II units, thought to be vertical cells in the DCN, receive auditory nerve inputs (horizontal line) from fibers with BFs matched closely to that of type IV units and inhibit type IV units to narrowband stimuli (Young 1980; Voigt and Young 1990). The WBIs, thought to be onset-C neurons in
A

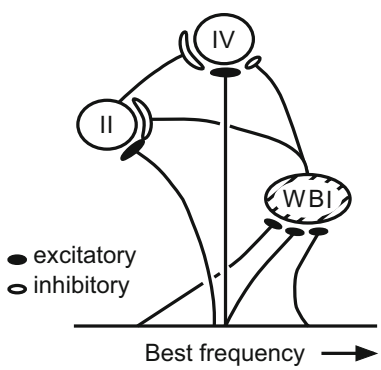

B

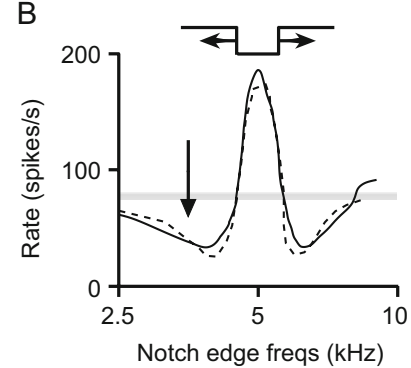

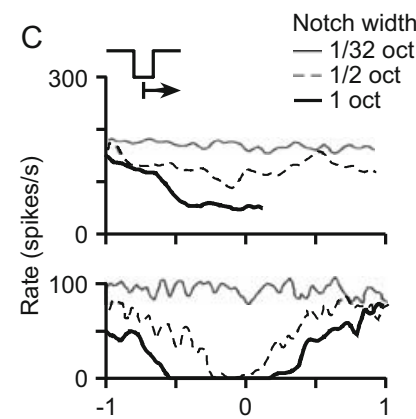

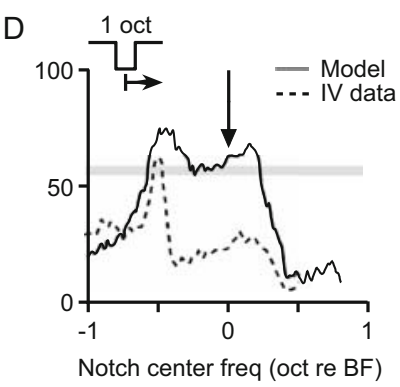

FIG. 1. A Conceptual model of the dorsal cochlear nucleus (DCN). Type IV unit responses to sound are shaped in part by inhibitory inputs from wideband inhibitors (WBIs). Filled (empty) ovals: excitatory (inhibitory) connections; size of a synapse: proportional to strength. Horizontal line: tonotopic array of auditory nerve (AN) inputs to the $\mathrm{CN}$; vertical lines: $\mathrm{AN}$ inputs of different best frequencies (BFs) connecting to $\mathrm{CN}$ units. B Best fit of the computational model of Hancock and Voigt (1999) to data derived from a type IV unit's responses to notch noise; in this model, all WBI cells had wide integration bandwidths. Notches were centered on unit BF and increased in width (inset). Responses are plotted at both the falling and rising edge frequency of the notch. Gray bar: spontaneous rate of type IV unit. Arrow: simulated and real type IV units were inhibited by a one-octave-wide notch centered on unit BF. C Responses of two onset- $C$ units, thought to be the neural correlates of the WBI, to notch noise sweeps (inset) plotted versus notch center frequency. Different line types indicate different notch widths in octaves. Note that some onset-C units are unresponsive to oneoctave-wide notches centered on unit BF. D Comparison of simulated and averaged low-rate type IV unit responses to a oneoctave-wide notch noise sweep plotted versus notch center frequency; in this model, all WBI cells had narrow integration bandwidths. Arrow: simulated response failed to show inhibition to a one-octavewide notch centered on unit BF. C and D modified from Reiss and Young (2005). the ventral cochlear nucleus, receive auditory nerve inputs over a wide $\mathrm{BF}$ range, on the order of three octaves wide, and inhibit type IV (and type II) units to wideband stimuli (Nelken and Young 1994; Winter and Palmer 1995; Jiang et al. 1996; Palmer et al. 1996). Thus, it has been hypothesized that WBIs, with wide input bandwidths and narrow output projections (WINO WBIs), are primarily responsible for inhibiting type IV units in response to stimuli with spectral notches.

In support of this hypothesis, an early computational model of the DCN, based on the above conceptual model, found that a source of wideband inhibition is required to account for the notch noise responses of type IV units; inhibition from type II units alone is insufficient for this purpose (Hancock and Voigt 1999). Figure 1B demonstrates the extent to which this model with WINO WBIs can account quantitatively for principal cell responses to BFcentered notches as a function of notch width (inset). In this figure, the dashed line shows the discharge rate vs. notch edge frequency curve derived from a type IV unit's responses to notch-noise stimuli (frequency-scaled data from Spirou and Young 1991), and the solid line represents the best fit (least squares) of the model. Note that each response is plotted twice: once at the falling edge and once at the rising edge of a notch. Like the type IV unit, the model principal cell shows a strong excitatory response when the falling and rising edges of the notch are both at $5 \mathrm{kHz}$ (i.e., the stimulus is broadband noise) and then exhibits progressively weaker responses as the notch widens. For notch widths greater than $1 \mathrm{kHz}$ (inset), including notches one-octave wide (vertical arrow), both the type IV unit and the model principal cell are inhibited; this inhibitory response is stronger for narrower notches but weakens with increasing notch width.

Recent physiological and modeling results, however, call into question a central role for the WBI in shaping the notch sensitivity of type IV units (Reiss and Young 2005). Figure $1 \mathrm{C}$ shows the notch-noise responses of two onset-C units, the putative WBIs, to notches of varying width (different line types) whose centers have been swept from about one octave below to one octave above unit BF (inset). Onset-C units give strong excitatory responses to notches centered well away from BF, but exhibit weak responses when the notch is centered on $\mathrm{BF}$. The response rate at $\mathrm{BF}$ decreases with increasing notch width and becomes zero for some units for notches one octave wide (thick solid lines). This strong rate modulation suggests that the integration bandwidth of onset-C units is much smaller than three octaves and thus that the WBI is an unsuitable candidate to produce inhibition in type IV units in response to wide spectral notches. Indeed, when all WBI cells in the model of Hancock and Voigt are remodeled to be narrow-input narrow-output 
(NINO) cells, model principal cells (solid line in Fig. 1D), unlike type IV units (dashed line), are not inhibited by one-octave wide notches centered at unit $\mathrm{BF}$ (arrow). These results suggest the need to add a new component to the DCN model.

The goal of the present study was to test further whether the two-inhibitor model of the DCN, in particular the WBI, is able to account fully for the notch sensitivity of type IV units. The model of DCN type IV units developed by Hancock and Voigt (1999) as modified by Reiss and Young (2005) served as the baseline. In particular, the bandwidth of auditory nerve fiber input to the $\mathrm{W}$-cells was fixed and narrow. The bandwidth of the projections from WBI to principal cells was then increased consistent with anatomical studies suggesting that single onset-C units innervate one third or more of the mediolateral extent (tonotopic axis) of the DCN (Oertel et al. 1990; Doucet and Ryugo 1997; Arnott et al. 2004). Given the frequency organization of the DCN (Spirou et al. 1993), this suggests that the output bandwidths of WBI cells are at least one octave wide. The results show that WBI cells with wide output bandwidths are able to produce strong inhibition in model principal cells for wide notch widths (without adversely affecting the responses of model cells to other basic stimuli). The results thus suggest that WBIs, in narrow-input wide-output (NIWO) form, are sufficient to account for the notch sensitivity of type IV units.

\section{METHODS}

\section{Organization of the DCN model}

The current computational model of the DCN (Fig. 2A) is based on the model developed by Hancock and Voigt (1999) as modified by Reiss and Young (2005). It consists of five cell groups arranged into 1,000 isofrequency slices evenly spaced on a logarithmic scale from 1.25 to $40 \mathrm{kHz}$. Figure 2A shows the connections among the model cell groups within a single frequency slice, where P-cells represent DCN principal cells (type IV units), I2-cells represent inhibitory interneurons with type II properties, and W-cells represent the wideband inhibitor. Model auditory nerve (AN) fibers excite the $\mathrm{W}$-, I2-, and Pcells, W-cells inhibit both I2- and P-cells, and I2-cells inhibit P-cells. In addition to their sound-driven inputs, P-cells also receive inputs from nonspecific afferents (NSA), which provide spontaneous excitatory drive. This source is meant to account for the fact that DCN neurons remain spontaneously active after the cochlea is ablated (Koerber et al. 1966) and is modeled as a Poisson process with an intensity of $3,000 \mathrm{spikes} / \mathrm{s}$.

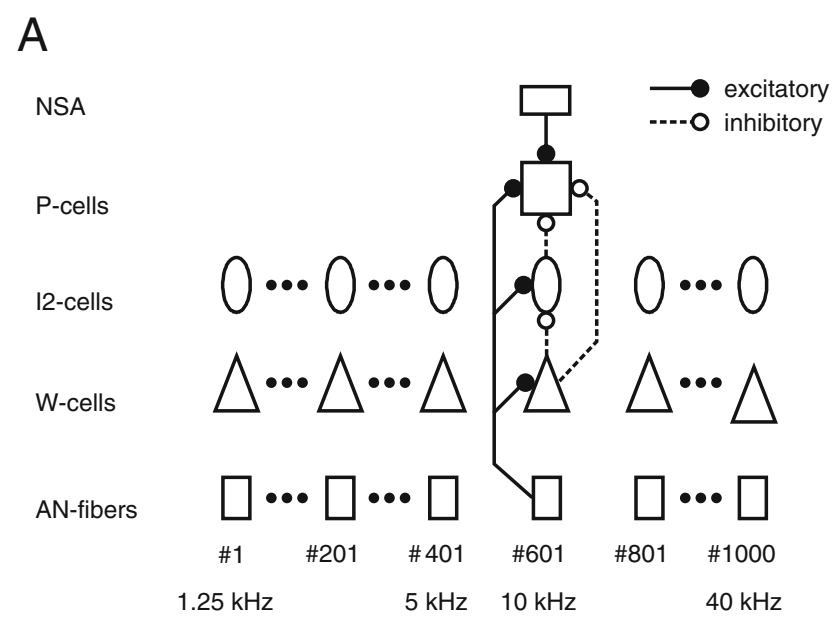

B

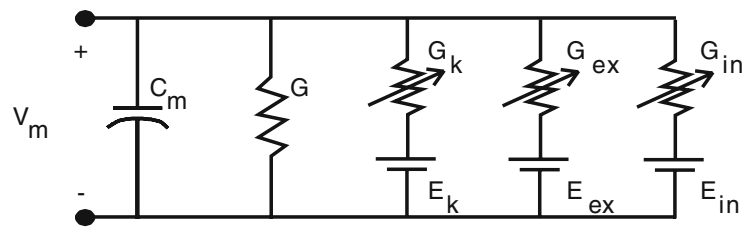

FIG. 2. Computational model of the DCN. A The DCN model consists of five cell populations organized in a tonotopic manner. Frequency increases in steps of 0.005 octaves. The populations are interconnected as shown. P-, I2-, and W-cells model type IV units, type II units, and WBIs, respectively, in the CN. NSA Nonspecific afferents, AN fibers, auditory nerve fibers. B CN cells are modeled as lumped-parameter electric circuits. $V_{\mathrm{m}}$ Membrane potential relative to rest, $C_{\mathrm{m}}$, membrane capacitance, $G$ resting conductance, $G_{\mathrm{k}}$ and $E_{\mathrm{k}}$, variable conductance and reversal potential for potassium, $G_{\mathrm{ex} / \mathrm{in}}$ and $E_{\text {ex/in }}$ variable conductance and reversal potential for excitatory/ inhibitory synaptic inputs.

The convergence from one model cell population onto another population is specified by three parameters. For generic source ("A") and target ("B") populations, each target cell "B" (e.g., a P-cell) receives $\mathrm{N}$ inputs from source cells "A" (e.g., I2-cells). These $\mathrm{N}_{\mathrm{A} \rightarrow \mathrm{B}}$ inputs are drawn randomly from a bandwidth, $\mathrm{BW}_{\mathrm{A} \rightarrow \mathrm{B}}$, octaves wide. The center frequency of this band is displaced by $\mathrm{C}_{\mathrm{A} \rightarrow \mathrm{B}}$ octaves from the $\mathrm{BF}$ of the target cell.

\section{Auditory nerve model}

AN fibers are based on the auditory nerve model described by Carney (1993) as modified by Zhang et al. (2001), Bruce et al. (2003), and Zilany and Bruce (2006). This model is valid over a wide range of frequencies and intensities spanning the dynamic range of hearing in cats. The model contains several sections, each of which provides a phenomenological description of a different part of the peripheral auditory system. Briefly, the model includes a middle ear filter (to set the minimum AN fiber threshold as a function of frequency), two signal-path filters (one of 
which establishes the BF and baseline tuning of a AN fiber), a feed-forward control path, an inner hair cell model section, followed by a synapse model and a spike generator. The input to the model is a sound pressure waveform, and the output is spike trains. In order to save time, all stimuli are processed by the auditory nerve model once and the AN-fibers' spike times are saved for use in subsequent simulations of the DCN model.

\section{Neuron model}

The neuromime (Fig. 2B) of MacGregor (1987) is used to model the cell membranes of individual cochlear nucleus cells. This model contains a number of parallel branches representing a membrane's capacitance, resting conductance, potassium channel, and synaptic inputs; no sodium channel is included because details related to action potential generation are omitted to reduce computation time. There is one synaptic branch for each population from which a cell draws input, where the sign of the reversal potential determines whether the connection is excitatory (ex) or inhibitory (in). In response to input spikes, synaptic conductances undergo a step increase $\delta_{\mathrm{A} \rightarrow \mathrm{B}}$ and exponential decay with a time constant $\tau_{\mathrm{A} \rightarrow \mathrm{B}}$.

Model cell spike times are recorded when a cell's membrane potential $\left(V_{\mathrm{m}}\right)$ exceeds its threshold $(\theta)$. Afterwards, the potassium conductance is activated to instill a refractory period (an absolute dead-time of $0.7 \mathrm{~ms}$ is enforced). The following three equations describe the neuromime model:

$$
\begin{gathered}
\tau_{m} \frac{d V_{m}}{d t}=-V_{m}-g_{k}\left(V_{m}-E_{k}\right)-g_{e x}\left(V_{m}-E_{e x}\right) \\
-g_{\text {in }}\left(V_{m}-E_{\text {in }}\right), \\
\tau_{k} \frac{d g_{k}}{d t}=-g_{k}+b_{k} S, \\
S=\left\{\begin{array}{ll}
0, & V_{\mathrm{m}}<\theta \\
1, & V_{\mathrm{m}} \geq \theta
\end{array}\right\}
\end{gathered}
$$

where $\tau_{\mathrm{m}}=C_{\mathrm{m}} / G, g_{\mathrm{k}}=G_{\mathrm{k}} / G, g_{\mathrm{ex}}=G_{\mathrm{ex}} / G, g_{\mathrm{in}}=G_{\mathrm{in}} / G$, and $b_{\mathrm{k}}$ and $\tau_{\mathrm{k}}$ are the step size and time constant, respectively, of the potassium conductance change after a spike $S$ occurs. For target cell B, the variable conductance change that represents the cumulative effect of synaptic activity by cells in population $\mathrm{A}$ is described by the following equation:

$$
\tau_{A \rightarrow B} \frac{d g_{A \rightarrow B}}{d t}=-g_{A \rightarrow B}+\delta_{A \rightarrow B} \sum_{i=1}^{N_{A \rightarrow B}} W_{i} S_{A i}
$$

where $W_{i}$ are synaptic weights and $S_{\mathrm{A} i}$ are the input spikes. The synaptic weighting function $W_{i}$ is uniformly distributed $\left(W_{i}=1\right)$ for all connections except for the AN fiber-W cell connection for which it is Gaussian-distributed (see below for details). This set of first-order differential equations is solved numerically using an exponential integration scheme (MacGregor 1987), where derivatives are assumed to be constant over each $0.1 \mathrm{~ms}$ time step, and exact solutions are used to update the state variables.

\section{Parameter values}

The parameters that specify the model fall into two groups: intrinsic and connection parameters. Four intrinsic parameters $\left(\tau_{\mathrm{m}}, \theta, b_{\mathrm{K}}\right.$, and $\left.\tau_{\mathrm{K}}\right)$ describe the membrane properties of a particular cell. Intracellular recordings in slice preparations have identified the membrane characteristics of many cochlear nucleus neuronal types (e.g., Manis 1990). Some of these properties have been confirmed in vivo (e.g., Hancock and Voigt 2002). The intrinsic parameter set determines the threshold sound pressure level (SPL) and the maximum steady-state firing rate of a model cell, but has little effect on a cell's spectral response characteristics (i.e., the rates between these limits; Hancock and Voigt 1999) that are the focus of this paper. The values used in this study (Table 1) are the same as those used by Hancock and Voigt (1999), except for slight differences in the $\theta$ and $b_{\mathrm{k}}$ values for the $\mathrm{W}$-cells. The $\theta$ parameter, in particular, is slightly higher than in the prior study to ensure that no W-cell at any frequency has a threshold below $0 \mathrm{~dB}$ spectrum level (SL) in response to a one-octave wide notchnoise stimulus logarithmically centered at its $\mathrm{BF}$.

Five connection parameters $\left(C_{\mathrm{A} \rightarrow \mathrm{B}}, \mathrm{BW}_{\mathrm{A} \rightarrow \mathrm{B}}, N_{\mathrm{A} \rightarrow \mathrm{B}}\right.$,

\begin{tabular}{|c|c|c|c|c|c|c|c|}
\hline \multicolumn{8}{|c|}{ Intrinsic parameters } \\
\hline Population & $\tau_{m}(m s)$ & $\theta(m V)$ & $b_{k}$ & $\tau_{k}(m s)$ & $E_{k}(m V)$ & $E_{e x}(m V)$ & $E_{\text {in }}(m V)$ \\
\hline W-cells & 5 & 4.25 & 1.5 & 1 & -10 & 70 & -10 \\
\hline I2-cells & 6 & 14.5 & 1.75 & 1 & -10 & 70 & -10 \\
\hline P-cells & 10 & 7.5 & 2 & 1 & -10 & 70 & -10 \\
\hline
\end{tabular}
$\delta_{\mathrm{A} \rightarrow \mathrm{B}}$, and $\left.\tau_{\mathrm{A} \rightarrow \mathrm{B}}\right)$ describe the connectivity within the network, and have the greatest effect on the spectral sensitivity of model cochlear nucleus cells. The values

TABLE 1 
used in this study (Table 2) are essentially the same as those used by Hancock and Voigt (1999) as modified by Reiss and Young (2005). In particular, the center of the $\mathrm{W}$-cell input to an I-cell $\left(C_{\mathrm{W} \rightarrow \mathrm{I} 2}\right)$ is offset by +0.3 octaves (rather than 0 octaves) to account for the asymmetric response of type II units to notch-noise sweeps (Reiss and Young 2005), and the center of the I2-cell input to a P-cell is offset by -0.1 octaves (rather than 0 octaves) to account for the asymmetric pattern of tonal inhibition of type IV units (Spirou and Young 1991). Together, these changes suggest that $C_{\mathrm{W} \rightarrow \mathrm{P}}$ be offset by +0.2 octaves. In addition, the synaptic weighting function for the AN-fiber input to a W-cell $\left(\mathrm{W}_{\mathrm{AN} \rightarrow \mathrm{W}}\right)$ is Gaussian distributed (rather than uniformly distributed) such that the average $\delta_{\mathrm{AN} \rightarrow \mathrm{W}}$ is 0.05 , but that the largest weights are concentrated near a W-cell's BF. Weights are computed according to the following equation:

$$
W_{i}=\frac{N_{0, \sigma^{2}}\left(x_{i}\right)}{\int_{-B W / 2}^{B W / 2} N_{0, \sigma^{2}}\left(x_{i}\right) / B W}
$$

where $i$ equals 1 to $N_{\mathrm{AN} \rightarrow \mathrm{W}}, N_{0, \sigma^{2}}$ is a Gaussian distribution with a mean of zero and a variance of $\sigma^{2}$ octaves, BW is 2.5 octaves, and $x_{i}$ equals the octave ratio of the $\mathrm{BF}$ of the $i$ th $\mathrm{AN}$-fiber input and the $\mathrm{BF}$ of the W-cell target (i.e., $\left.\log _{2}\left(\mathrm{BF}_{\mathrm{ANi}} / \mathrm{BF}_{\mathrm{W}}\right)\right)$. The effective bandwidth of AN-fiber input to the W-cells $\left(\mathrm{BW}_{\mathrm{AN} \rightarrow \mathrm{W}}\right)$ was defined to be $2 \sigma$.

\section{Simulation protocol and data analysis}

All test stimuli, including tones, noise, notch noise, and noise bands were $200 \mathrm{~ms}$ in duration, gated on and off using a raised cosine ramp with $5 \mathrm{~ms}$ rise/fall times and presented once per $400 \mathrm{~ms}$. Noise spectra were defined in the frequency domain, each with a 49$\mathrm{kHz}$ bandwidth and converted to time domain pressure waveforms by taking the inverse Fourier transform (at a sampling rate of $500 \mathrm{kHz}$ as required

\begin{tabular}{lllrlr}
\hline \multicolumn{5}{c}{ TABLE 2 } \\
\hline \multicolumn{5}{c}{ Connection parameters } \\
\hline $\begin{array}{l}\text { Connection } \\
A \rightarrow B\end{array}$ & $C_{A \rightarrow B}($ oct $)$ & $B W_{A \rightarrow B}($ oct $)$ & $N_{A \rightarrow B}$ & $\delta_{A \rightarrow B}$ & $\tau_{A \rightarrow B}(m s)$ \\
\hline $\mathrm{AN} \rightarrow \mathrm{W}$ & 0 & $2.5^{\mathrm{a}}$ & 140 & 0.05 & 10 \\
$\mathrm{AN} \rightarrow \mathrm{I} 2$ & 0 & 0.4 & 48 & 0.55 & 10 \\
$\mathrm{AN} \rightarrow \mathrm{P}$ & 0 & 0.4 & 48 & 0.25 & 10 \\
$\mathrm{~W} \rightarrow \mid 2$ & 0.3 & Varies & 15 & 1.4 & 10 \\
$\mathrm{~W} \rightarrow \mathrm{P}$ & 0.2 & Varies & 15 & Varies & 10 \\
$\mathrm{I} \rightarrow \mathrm{P}$ & -0.1 & 0.2 & 21 & 2.25 & 1 \\
$\mathrm{NSA} \rightarrow \mathrm{P}$ & $\mathrm{n} / \mathrm{a}$ & n/a & 1 & 1 & 3 \\
\hline
\end{tabular}

${ }^{a}$ Bandwidth is effectively 0.83 because of Gaussian-distributed weighting of inputs. by the auditory nerve model). Notch-noise spectra had infinite edge slopes and notch depths; noise band spectra had complementary shapes.

Rate-level data were obtained by sweeping the level of BF tones or broadband noise bursts over an 80-dB range in 1-dB steps. Frequency response maps were created by sweeping the frequency of tone bursts over a three-octave range centered on unit BF. These frequency sweeps were presented at multiple levels, ranging from $\sim 10 \mathrm{~dB}$ below to $\sim 50 \mathrm{~dB}$ above threshold. Each frequency-intensity combination was presented once. Notch-noise and noise band sweep series consisted of 91 stimuli with logarithmically constant notch or band widths $(0.5$ or 1 octaves wide) and center frequencies ranging from 1.5 octaves below to 1.5 octaves above unit BF in 0.033 octave steps. Notch widening data were obtained by presenting notches arithmetically centered on unit BF and increasing the notch width in $1-\mathrm{kHz}$ steps. All notch-noise and noise band stimuli were presented at a pass-band spectrum level of $0 \mathrm{~dB}(\sim 47 \mathrm{~dB}$ SPL for signals with a 49-kHz bandwidth).

In all simulations, the effective AN-fiber input bandwidth of the W-cells $\left(\mathrm{BW}_{\mathrm{AN} \rightarrow \mathrm{W}}\right)$ was fixed and narrow ( 0.83 octaves; $\sigma=0.42$ octaves) to ensure that $\mathrm{W}$-cell responses were $100 \%$ modulated by one-octave wide notch sweeps (Reiss and Young 2005). To examine the effect of W-cell output bandwidth on I2 and P-cell response properties, the bandwidths of the $\mathrm{W}-\mathrm{I} 2$ and $\mathrm{W}-\mathrm{P}$ cell connections $\left(\mathrm{BW}_{\mathrm{W} \rightarrow \mathrm{I} 2}\right.$ and $\left.\mathrm{BW}_{\mathrm{W} \rightarrow \mathrm{P}}\right)$ were (co)varied from 0.1 to 3.0 octaves in steps of 0.5 octaves, and the strength of the $\mathrm{W}-\mathrm{P}$ cell connection $\left(\delta_{\mathrm{W} \rightarrow \mathrm{P}}\right)$ was varied from 0 to 1.2 in increments of 0.2 .

The responses elicited by test stimuli are described in terms of average rates. Stimulus-evoked firing rates were computed as the average firing rate over the last $160 \mathrm{~ms}$ of the stimulus-on period to reflect steady-state responses. Spontaneous rates were computed as the average firing rate over the last $100 \mathrm{~ms}$ of the stimulusoff period. All data were smoothed with a three-point triangular moving window filter (with coefficients of $1 / 4,1 / 2,1 / 4)$ to reduce noise.

\section{RESULTS}

The primary objective of the present modeling study was to test whether W-cells with narrow input bandwidths but wide output bandwidths could produce strong inhibition in P-cells for wide notches centered near unit BF. The responses of P-cells to other stimuli, including tones, broadband noise, notch noise, and noise bands, were then simulated to explore whether this version of the two-inhibitor model can replicate the known physiology of DCN type IV units. 
Effects of W-cell output bandwidth on DCN unit notch-noise responses

In all of the simulations described in this study, model W-cells received AN-fiber inputs over a 2.5-octave range, but the inputs were Gaussian-weighted such that the effective input bandwidth (defined here to be $2 \sigma$ ) was limited to 0.83 octaves. The response properties of a representative $(12 \mathrm{kHz}) \mathrm{W}$-cell are shown in Fig. 3. The rate versus level curves in Fig. 3A show that all W-cells lacked spontaneous activity and responded better to broadband noise (solid line) than to $\mathrm{BF}$ tones (dashed line). That is, W-cells had slightly lower thresholds, showed steeper rate-level curves, and achieved higher discharge rates to noise than to tones. In response to notch noise sweeps (Fig. 3B) at 0 dB SL ( 47 dB SPL), W-cells showed strong excitatory responses for notches located remote from $\mathrm{BF}$, and weak responses when the notch was centered on unit BF. Also note that the responses were smaller for wide notch widths (one octave wide; solid line) than for narrow notch widths $(0.5$ octaves wide; dashed line). The electrical threshold of W-cells (Table 1) was set to ensure that W-cells at all frequencies (the lowest AN-fiber thresholds occur around $9 \mathrm{kHz}$ ) showed a $100 \%$ rate modulation for one octave wide notch sweeps at $0 \mathrm{~dB}$ SL.

Figure 4 illustrates how inhibition from W-cells shapes I2-cell responses to one-octave wide notch noise sweeps. The third panel of this figure (Fig. 4C) shows the responses of the 12-kHz I2-cell, and the first two panels show the total combined activity of the populations of excitatory AN fiber (Fig. 4A) and inhibitory W-cell inputs (Fig. 4B) that contact this single I2-cell. The different line types in panels $4 \mathrm{~b}$ and $4 c$ show the effects of increasing the output bandwidth of the $\mathrm{W}$-cells on the cumulative $\mathrm{W}$-cell input and I2-cell output, respectively. The strong rate modulation of the cumulative AN-fiber response (Fig. 4A) by notch center frequency reflects the facts that each AN fiber in the population is narrowly tuned, and the bandwidth of the AN-I2 cell connection is limited to 0.4 octaves. Similarly, when the bandwidth of the W-I2 cell connection was tightly bandlimited ( 0.1 octaves), the cumulative W-cell response (solid line, Fig. 4B) resembled that of a single W-cell (e.g., Fig. 3B). In particular, the cumulative W-cell response was $100 \%$ modulated by notch center frequency. Note that the $\mathrm{BF}$ of the $\mathrm{W}$-cell input to an I2-cell was offset from that of the AN-fiber BF by +0.3 octaves, as suggested by Reiss and Young (2005). This offset endowed I2-cells with an asymmetric response to notch-noise stimuli with a peak response rate for notches centered $\sim 0.5$ octave above $\mathrm{BF}$ (solid line; Fig. $4 \mathrm{C}$ ), which is the response pattern exhibited by type II units in the DCN (Reiss and Young 2005).
A

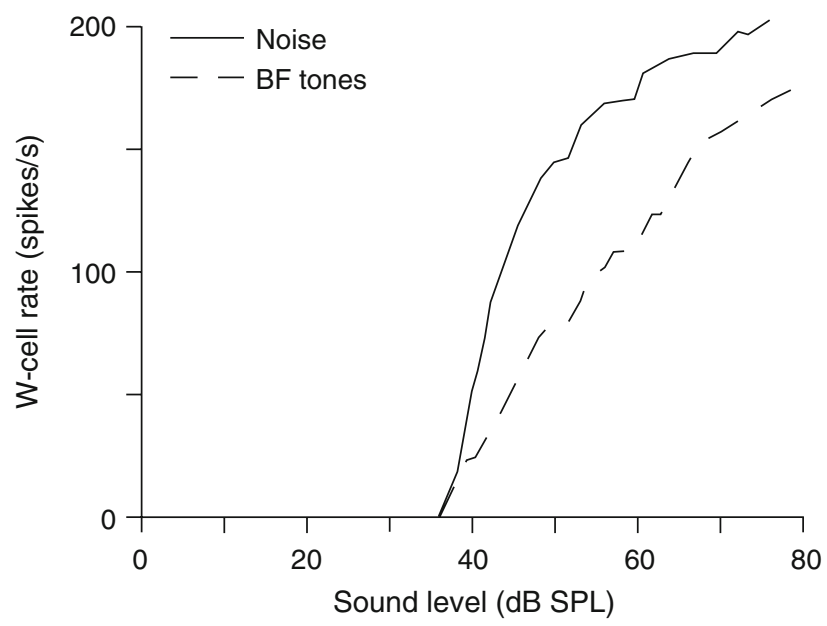

B

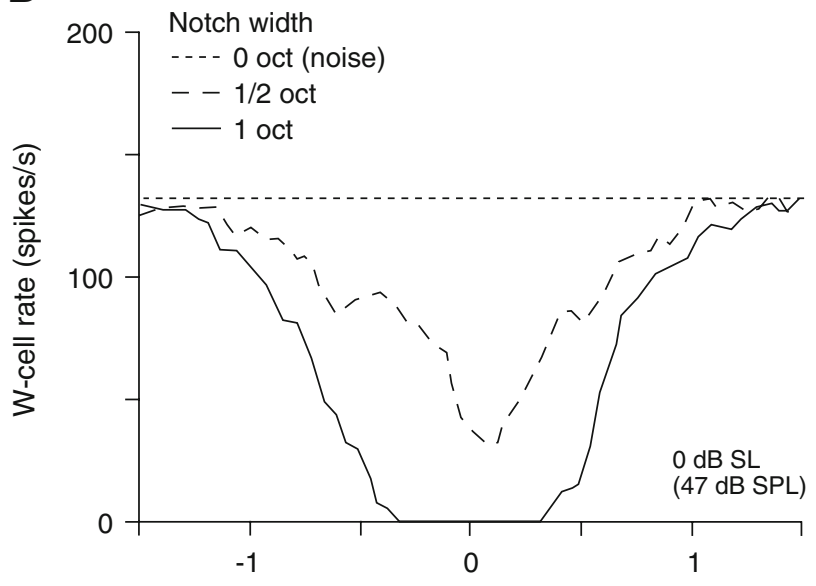

Notch center frequency (oct re W-cell BF)

FIG. 3. Response properties of a model W-cell. The effective bandwidth of auditory nerve inputs to all W-cells is relatively narrow (0.83 octaves). A Discharge rate versus sound level curves for BF tones and broadband noise. W-cells have comparable thresholds to tones and noise, and show stronger responses to noise than tones. B Responses to notch noise sweeps plotted versus notch center frequency. Different line types indicate different notch widths. Passband level was $0 \mathrm{~dB}$ spectrum level $(\mathrm{SL} ; 47 \mathrm{~dB}$ sound pressure level for signals with a $49-\mathrm{kHz}$ bandwidth). Parameters were set to ensure that all W-cells in the model showed $100 \%$ rate modulation to oneoctave-wide notch sweeps. BF, $12 \mathrm{kHz}$.

As the bandwidth of the W-I2 cell connection was increased from 0.1 to three octaves, the cumulative $\mathrm{W}$ cell input to the I2-cell became progressively less modulated (Fig. 4B; heavy solid line). Discharge rates decreased for notch center frequencies remote from the $\mathrm{BF}$ of the I2-cell because some W-cells inputs to the I2-cell had their BFs at those frequencies and thus were unresponsive, whereas the discharge rate for notch frequencies around the I2-cell $\mathrm{BF}$ increased because remote $\mathrm{W}$-cell inputs were responding strongly. In turn, the I2-cell response (Fig. 4C; heavy solid line) increased for notch frequencies remote to its $\mathrm{BF}$ 


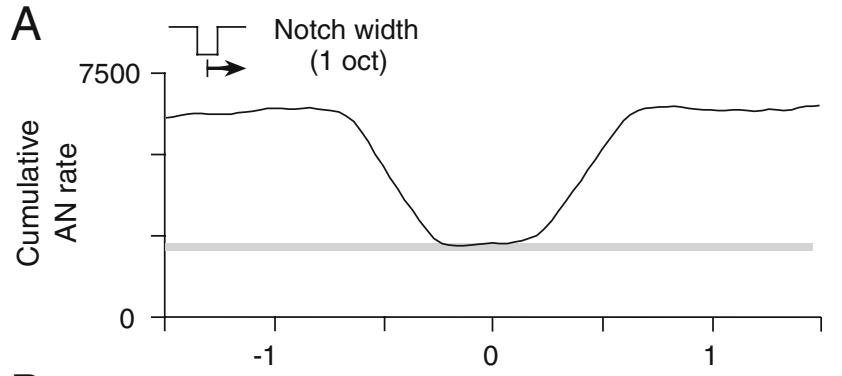

B

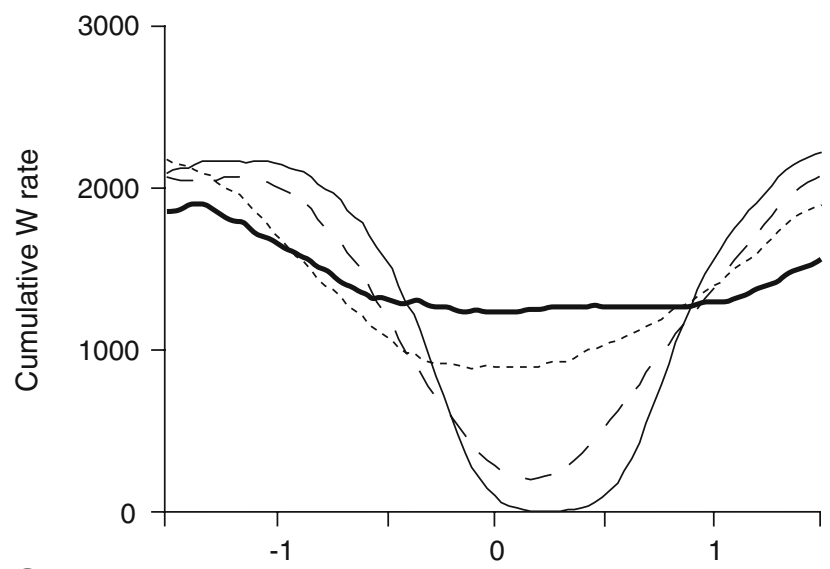

C

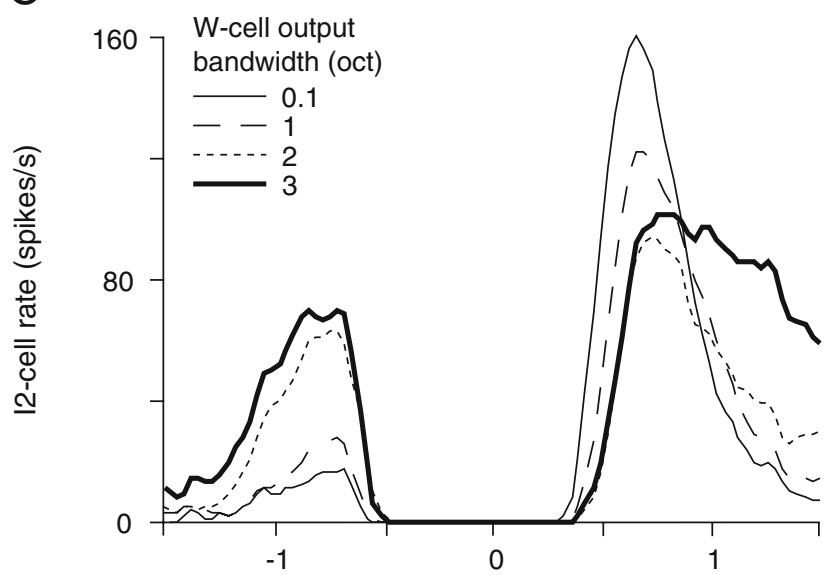

Notch center frequency (oct re 12-cell BF)

FIG. 4. Notch noise sweep responses of an 12-cell as a function of the bandwidth of the $\mathrm{W}-\mathrm{I} 2$ cell connection $\left(\mathrm{BW}_{\mathrm{W}-12}\right)$. A-C Cumulative excitatory AN fiber (A) and inhibitory W-cell inputs (B) to a single $(12 \mathrm{kHz})$ I2-cell $(\mathbf{C})$ in response to a one-octave-wide notch noise sweep at $0 \mathrm{~dB}$ SL. Different line types in $\mathbf{B}$ and $\mathbf{C}$ indicate different $B W_{W-12}$ in octaves. Modulation of $\mathrm{W}$-cell rate by notch frequency and an offset in $\mathrm{W}$-cell $\mathrm{BF}$ relative to $\mathrm{AN}$-fiber $\mathrm{BF}(+0.3$ octaves) endowed 12-cells with asymmetric notch noise responses. Increasing $\mathrm{BW}_{\mathrm{W}-12}$ decreases, but does not eliminate, the basic asymmetry in the 12-cell response.

and decreased for notch center frequencies nearer to its $\mathrm{BF}$, including those that elicited the peak response rate. I2-cell responses for notch center frequencies at unit $\mathrm{BF}$ were unchanged because the cell was already unresponsive to those stimuli. Importantly, due to the facts that the center of the W-cell input is displaced relative to the $\mathrm{BF}$ of its I2-cell target, and the cumulative W-cell response retained some rate modulation to notch frequency, the I2-cell response remained asymmetric like that of type II units for increasing W-I2 cell bandwidth.

Figure 5 shows the effects of inhibition from Wcells on P-cell responses to notch-noise sweeps when the $\mathrm{W}$ cell output bandwidth was narrow ( 0.1 octaves). Figure 5A shows the cumulative discharge rates in response to a one-octave wide notch noise sweep of the populations of excitatory AN-fiber (solid line), and inhibitory I2 (dashed line) and W-cell inputs (heavy solid line) that contact a single P-cell, and Fig. 5B shows the response of the target $12 \mathrm{kHz}$ P-cell.

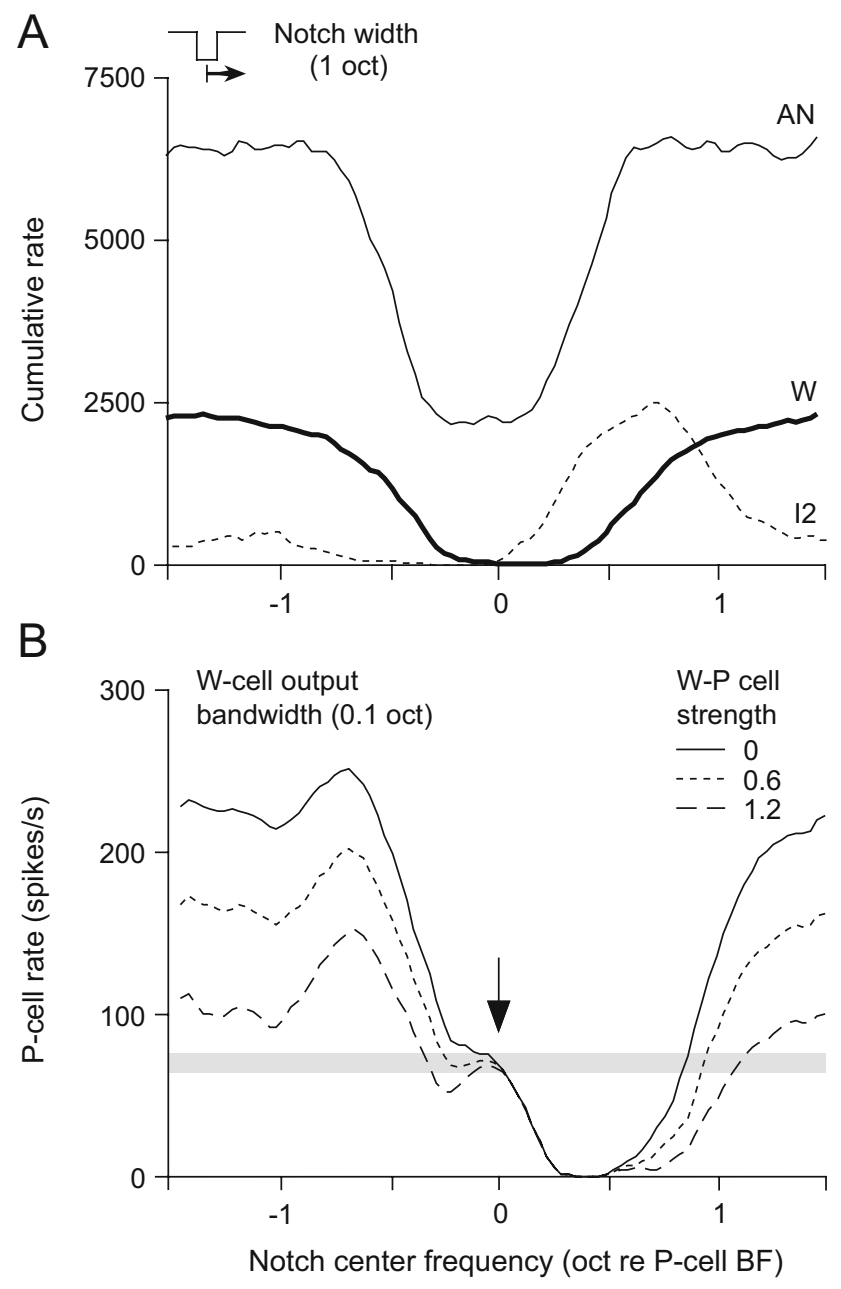

FIG. 5. Effects of $W$-cell inputs on P-cells when the output bandwidth of $\mathrm{W}$-cells is narrow. A-B Cumulative excitatory AN fiber, and inhibitory I2-cell and $\mathrm{W}$-cell inputs $(\mathbf{A})$ to the $12-\mathrm{kHz}$ P-cell (B) in response to a one-octave-wide notch noise sweep at $0 \mathrm{~dB}$ SL. Increasing the strength of the W-P cell connection reduces the discharge rate of the $\mathrm{P}$-cell for notch frequencies away from $\mathrm{BF}$, but does not produce inhibition of the P-cell for notches centered at BF (arrow). 
As shown in Fig. 5A, the BF of the I2-cell inputs to the P-cell was offset -0.1 octaves relative to the $\mathrm{BF}$ of the AN-fiber inputs, as suggested by the response map data of Spirou and Young (1991); therefore, the center of the $\mathrm{W}$-cell input was +0.2 octaves relative to $\mathrm{BF}$ of the P-cell. Note that the cumulative inhibitory I2 and $\mathrm{W}$-cell inputs to the P-cell were zero at the BF of the P-cell.

The solid line in Fig. 5B shows the response of the P-cell to its excitatory AN fiber and inhibitory I2-cell inputs without W-cell input (i.e., the strength of the $\mathrm{W}-\mathrm{P}$ cell connection was set to zero). As a function of notch center frequency, the P-cell showed a small decrease in rates, a slightly asymmetric rate peak for notches centered $\sim 0.5$ octave below $\mathrm{BF}$, a plateau, a rate trough for notches centered $\sim 0.5$ octave above $\mathrm{BF}$, and then a large increase in rates. The peak and trough features of this response, including the shape of the peak (which can be made more asymmetric by increasing the I2-P connection bandwidth to decrease the rising slope of the peak or decreasing the AN-P bandwidth to increase the falling slope of the peak), are observed in type IV unit responses (Reiss and Young 2005). The rate increases for notches remote to $\mathrm{BF}$ were not observed in type IV units; however, this discrepancy can be readily explained. Rates at these remote notch locations must approach that of broadband noise at that stimulus level; most units recorded by Reiss and Young were weakly inhibited by noise, whereas the model cells were strongly excited by noise (see Fig. 8D) as is more typical of type IV units (Young and Brownell 1976). Importantly, for notches centered near BF, the P-cell showed no driven activity (arrow), whereas type IV units nearly always show inhibition. Adding inhibitory inputs from the W-cells reduced the discharge rates of the P-cell at many notch frequencies (dashed lines), particularly those remote to $\mathrm{BF}$, but did not produce $\mathrm{P}$-cell inhibition at notch frequencies near BF because the W-cells were not excited by these stimuli.

The effects of increasing the output bandwidth of W-cells on P-cell responses to notch noise sweeps is shown in Fig. 6. Each of the first three panels (Figs. 6A-C) shows the responses of the 12-kHz P-cell as a function of the bandwidth of the $\mathrm{W}-\mathrm{P}$ cell connection at a fixed $\mathrm{W}-\mathrm{P}$ cell strength. In Fig. 6A, the strength of the $\mathrm{W}-\mathrm{P}$ connection is set to zero, so that all of the changes can be attributed to the indirect effects of the $\mathrm{W}$-cells on the I2-cell inputs to this model P-cell (recall that the W-I2 and W-P cell

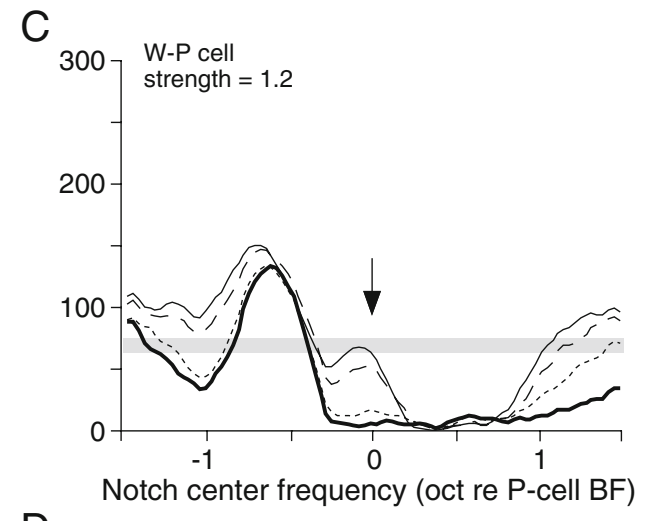

D
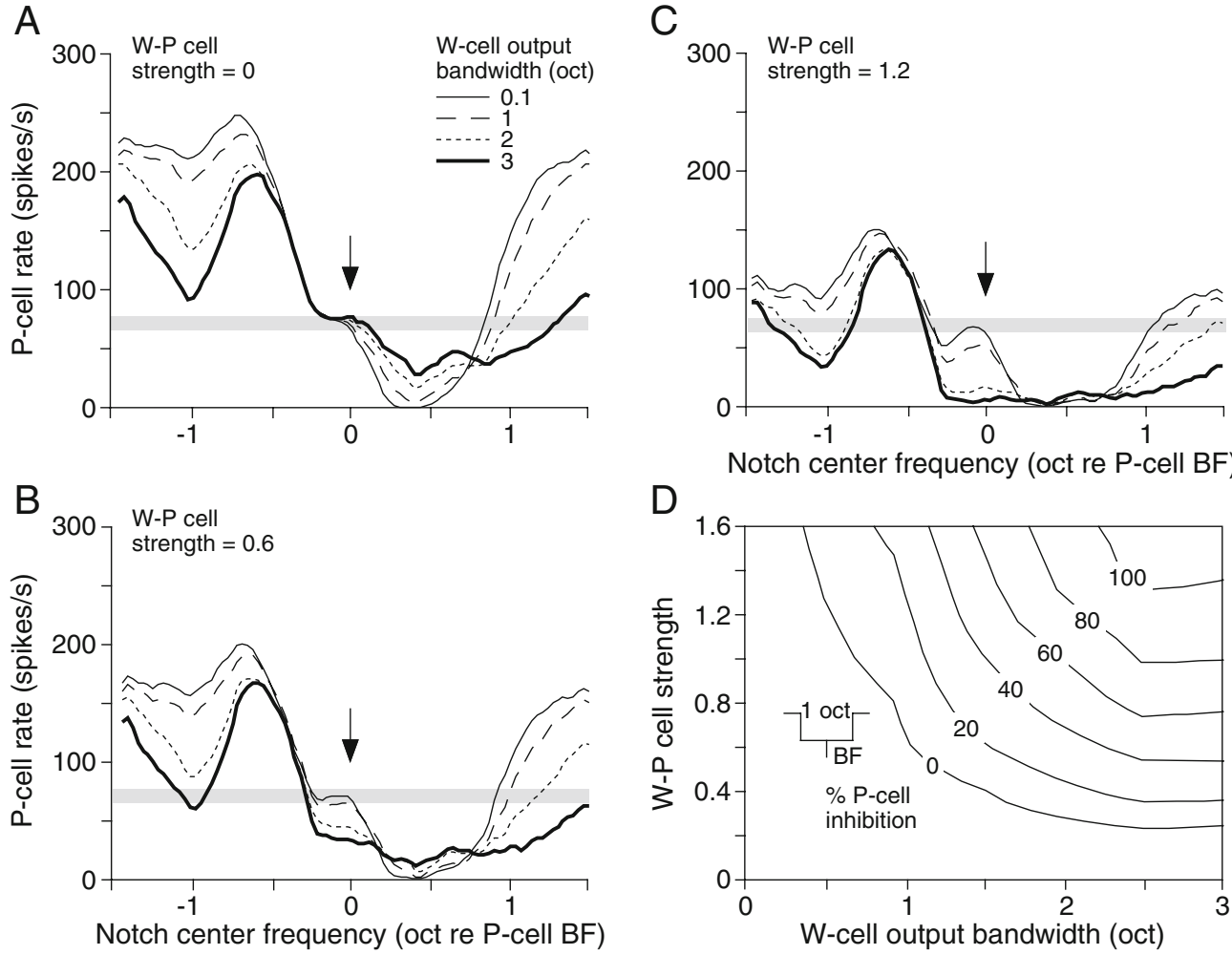

FIG. 6. Effects of W-cell inputs on P-cells for different W-P (and W-I2) projection bandwidths and W-P cell synaptic strengths. A-C Notch noise sweep responses of the $12-\mathrm{kHz}$ P-cell as a function of the bandwidth of the $\mathrm{W}-\mathrm{P}$ cell connection (BW $\left.\mathrm{W}_{-\mathrm{P}}\right)$ at fixed $\mathrm{W}-\mathrm{P}$ cell synaptic strengths $\left(\delta_{\mathrm{W} \rightarrow \mathrm{P}}\right)$. The notch width was one-octave wide. Different line types indicate different BW $\mathrm{W}_{\mathrm{P}}$ in octaves; $\delta_{\mathrm{W} \rightarrow \mathrm{P}}$ is indicated on the plot. Increasing $\mathrm{BW}_{\mathrm{W}-\mathrm{P}}$ and $\delta_{\mathrm{W} \rightarrow \mathrm{P}}$ increase the strength of inhibition of P-cells in response to notches centered at BF (arrows). D Summary of BW $\mathrm{W-P}$ and $\delta_{\mathrm{W} \rightarrow \mathrm{P}}$ effects on P-cell notch responses at BF. Lines indicate contours of equal percent P-cell inhibition. 
output bandwidths covary). Note that for a W-P cell bandwidth of 0.1 octaves, the P-cell (solid line) shows a rate peak for notches located below $\mathrm{BF}$, a rate trough for notches located above $\mathrm{BF}$, and no driven activity for notches near BF (arrow). When the bandwidth of the $\mathrm{W}-\mathrm{P}$ cell connection increases to three octaves (heavy solid line), the P-cell response to notches remote to $\mathrm{BF}$ decreases because of the increased activity of the I2-cell inputs to this cell (see Fig. 4C), but the response at BF is essentially unchanged. Adding inhibitory inputs from the $\mathrm{W}$ cells at an intermediate strength $\left(\delta_{\mathrm{W}-\mathrm{P}}=0.6\right.$; Fig. $\left.6 \mathrm{~B}\right)$ increases further the inhibition of P-cell responses to notches remote to $\mathrm{BF}$, but also inhibits the P-cell to notches centered on BF (arrow). With increasing strength of the $\mathrm{W}-\mathrm{P}$ cell connection (Fig. 6C), the inhibition at $\mathrm{BF}$ can be made to be complete.

Figure 6D summarizes the effects of inhibition from W-cell inputs to P-cells as a function of W-P cell bandwidth and synaptic strength. To create this figure, P-cell responses to one-octave wide notch sweeps were obtained for a variety of $\mathrm{W}-\mathrm{P}$ cell connection bandwidths $(0.1$ to three octaves in 0.5 octave steps) and $\mathrm{W}-\mathrm{P}$ cell synaptic strengths (0 to 1.2 in 0.1 steps). The percent inhibition at $\mathrm{BF}$ was measured and averaged across the six P-cells from 9 to $14 \mathrm{kHz}$ in $1-\mathrm{kHz}$ steps. The final results were then smoothed with a spatial filter and contours of equal percent inhibition labeled. The results show that for $\mathrm{W}-\mathrm{P}$ cell connection bandwidths below about 0.5 octaves, and $\mathrm{W}-\mathrm{P}$ cell synaptic strengths below 0.2 , Wcells are unable to inhibit P-cells for notches centered on BF. However, for wider $\mathrm{W}-\mathrm{P}$ cell bandwidths and stronger $\mathrm{W}-\mathrm{P}$ cell synaptic strengths, W-cells in narrow-input wide-output form are sufficient to inhibit P-cells to a desired percent inhibition.

The results above demonstrate that the model does not reproduce qualitatively typical type IV unit responses to one-octave wide notches centered on $\mathrm{BF}$ when the WBIs have a narrow output bandwidth (NINO model), but does show appropriate responses when the WBIs have a wide output bandwidth (NIWO model). This is put on a more quantitative basis and extended to other notch widths in Fig. 7, which shows a plot of discharge rate as a function of notch width. The circles shows data derived from a type IV unit in decerebrate cat $(B F=13.1 \mathrm{kHz}$; Spirou and Young 1991), and the lines show the responses of a BFmatched P-cell for two selected W-cell output bandwidths ( 0.1 vs. 2.2 octaves). The model fits were optimized by adjusting the strength of the W-P connection $\left(\delta_{\mathrm{W} \rightarrow \mathrm{P}}\right)$ to produce a P-cell which showed similar broadband noise and maximum notch-noise inhibitory responses to that of the type IV unit; the optimal $\delta_{\mathrm{W} \rightarrow \mathrm{P}}$ was 0.6 . All other parameter values were the same as those used before (the base set of values

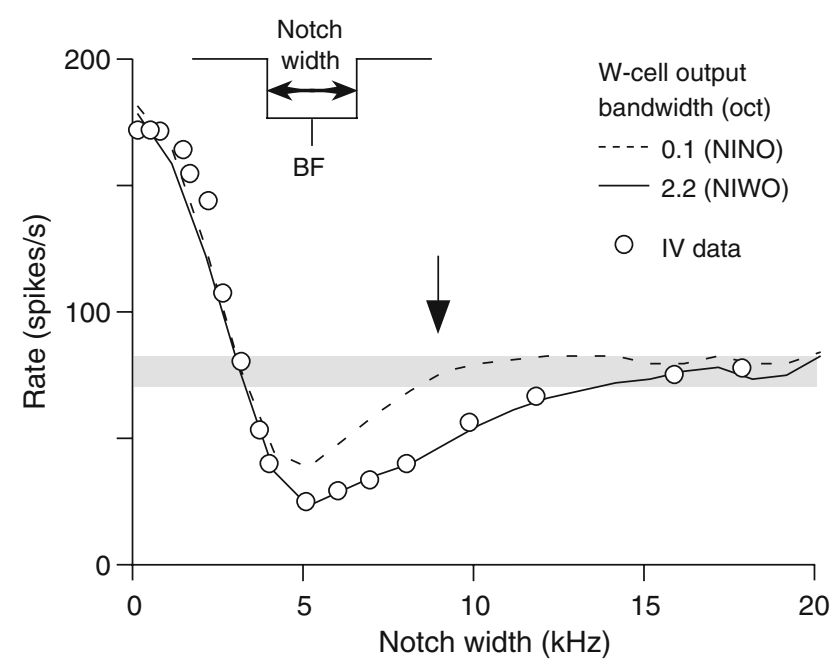

FIG. 7. Comparison of model P-cell and DCN type IV unit responses to notch noise stimuli. Notches were centered on unit BF and increased arithmetically in width. The shaded bar shows the range of spontaneous rates of the type IV unit. The P-cell response fails to match that of the type IV unit when the connections from $\mathrm{W}_{-}$ P-cells are bandlimited ( 0.1 octaves; dotted line), but matches closely that of the type IV unit when the BW $\mathrm{W}_{\mathrm{P}-\mathrm{P}}$ was wide (2.2 octaves; solid line). The notch is approximately one-octave wide at the arrow.

chosen for this study was near to that found to provide an optimal fit to these data by Hancock and Voigt 1999). Note that the P-cell in the NIWO model (solid line), like the type IV unit (circles), showed excitation for narrow notch widths and inhibition for a wide range of wider notches centered on unit BF (e.g., the arrow indicates the notch approximately one-octave wide). In contrast, the P-cell in the NINO model (dashed line) failed to show inhibitory responses for wider notches.

W-cell effects on DCN unit responses to a variety of simple and complex stimuli

Types II and IV units are characterized by their frequency response maps and responses to broadband noise, and have distinct responses to notch noise and noise band stimuli that contain spectral edges (Young and Brownell 1976; Young and Voigt 1982; Reiss and Young 2005). Figures 8 and 9 demonstrate the extent to which the two-inhibitor model with W-cells in NIWO form can replicate the known physiology of typical edge-sensitive types II and IV units and how variations in W-cell output bandwidth affect these results. For these simulations, the strength of the W-P cell connection was fixed at 0.6 , and the $\mathrm{W}$-cell output bandwidth was either wide (2.2 octaves) or narrow ( 0.1 octaves). Figure 10 then shows how simple modifications to the model with wide-output W-cells can reproduce the responses of type IV units without edge sensitivity. All results are shown for the case when the W-cell projections to their targets were given 
A
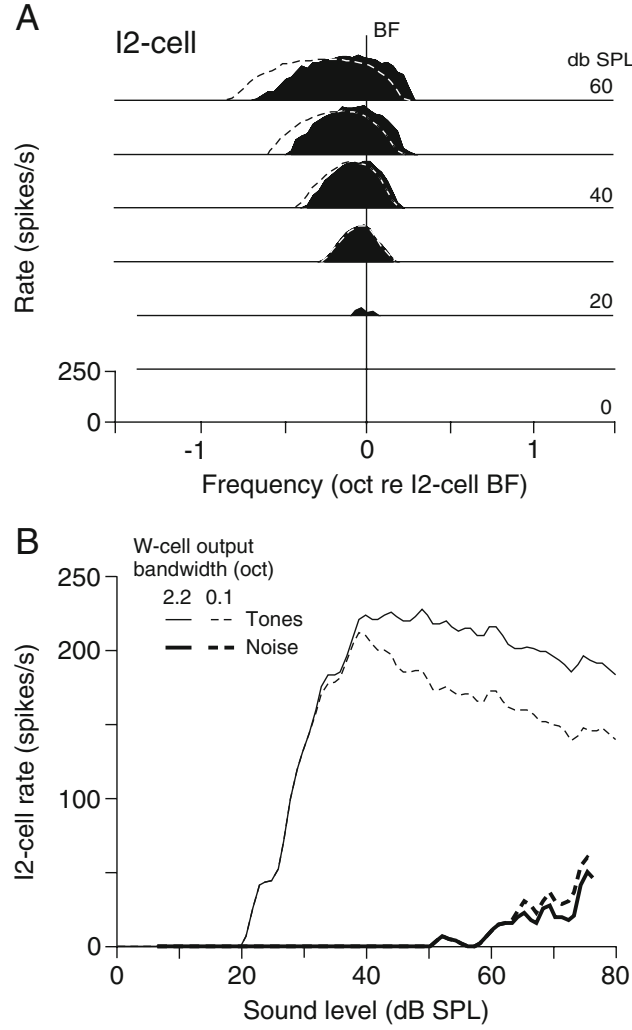

C

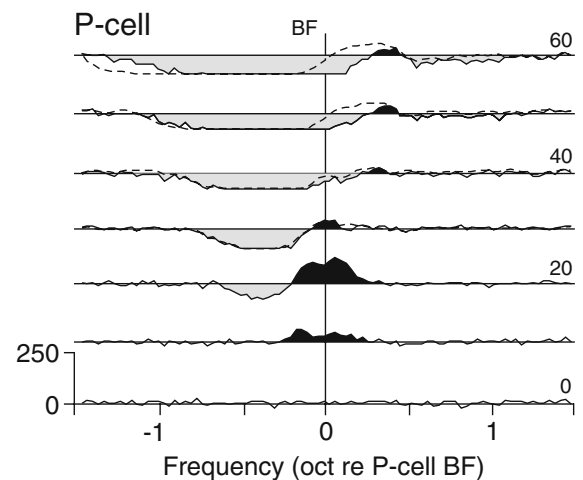

D

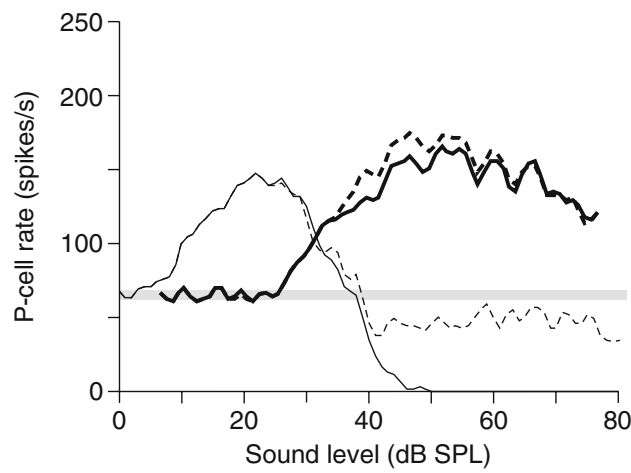

FIG. 8. Effects of W-cell output bandwidth on the frequency response maps and rate-level curves of edge-sensitive I2 (left) and P-cells (right). A, C Frequency response maps show stimulus-evoked discharge rates plotted against frequency at multiple sound pressure levels (numerical labels at right). Responses when the W-cell output bandwidth was wide (narrow) are shown as solid (dashed) lines; bandwidth was either 2.2 or 0.1 octaves wide. Horizontal lines represent spontaneous rates. Black (gray) regions identify excitatory (inhibitory) response areas when the Wcell output bandwidth was wide. Vertical lines indicate unit BFs. Note that when the output bandwidth of the W-cell was narrowed, the excitatory area of the 12-cell shifted to lower frequencies. In turn, the central inhibitory area of the P-cell shifted to lower frequencies. B, D Discharge rate versus sound level curves for BF-tones and broadband noise. Different line types indicate stimulus type and W-cell output bandwidth. Consistent with the response map data, the I2-cell showed a lower maximum rate to BF tones, and the P-cell showed reduced inhibition at higher stimulus levels when the output bandwidth of the W-cell was narrowed. Noise responses were largely unaffected by manipulations of W-cell output bandwidth.

uniform synaptic weights; the results are altered little if the synaptic weighting functions are changed to Gaussian distributions as long as the effective bandwidth $(2 \sigma)$ of the Gaussian distribution matches that of the uniform distribution (results not shown).

Figures $8 \mathrm{~A}$ and $\mathrm{C}$ show frequency response maps for the 12-kHz I2- and P-cells, respectively. These plots show discharge rate versus frequency functions at a series of sound pressure levels, given as dB SPL values at the right of the plots. Responses when the W-cell output was wideband are shown as solid lines, whereas responses when the $\mathrm{W}$-cell output was narrowband are shown as dashed lines. Excitatory areas (black-filled for the wideband case) are defined as stimulus conditions that elicited responses consistently above the spontaneous rate (SR; horizontal lines), and inhibitory areas (gray filled) are regions of rate below the SR. Vertical bars indicate the units' BF. In the wideband case, I2-cells (Fig. 8A) have a V-shaped excitatory area that widens symmetrically about unit $\mathrm{BF}$ with increasing sound level. These units do not show inhibitory responses to pure tones because they lack spontaneous activity. P-cell response maps (Fig. 8C) display an O-shaped island of excitation around BF threshold that gives way to inhibition at higher sound levels. For this cell, the region of highlevel inhibition is segregated into a central inhibitory area (CIA) and an upper inhibitory sideband (UIS) by an upper excitatory region consisting of excitatory responses to a narrow range of frequencies above $\mathrm{BF}$.

When the output bandwidth of the inhibitory Wcells was narrowed, W-cell activity increased for tones above the BF of the I2- and P-cells and decreased for tones below their BF (recall that the center of the $\mathrm{W}$ cell input to these cell types is offset by +0.3 and +0.2 octaves, respectively). Consequently, the I2-cell map (Fig. 8A; dashed lines) shifted towards lower frequencies at higher sound levels. A similar change in the Pcell response map was not observed (Fig. 8C; dashed line); rather, the opposite was observed. That is, the net effect on the P-cell response map was an increase in response rate at, and above, its $\mathrm{BF}$ and a decrease 

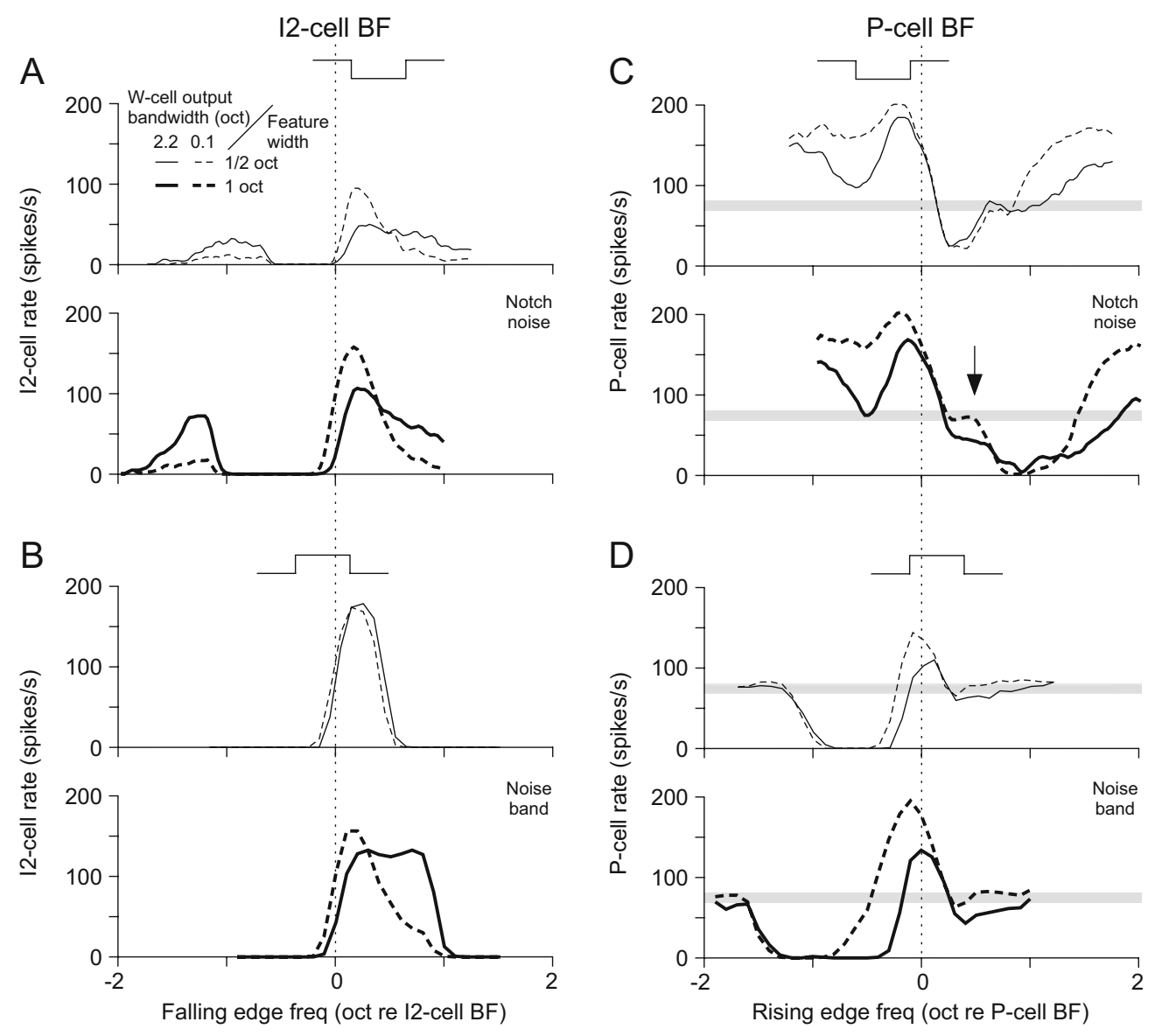

FIG. 9. Effects of W-cell output bandwidth on the notch noise and noise band responses of edge-sensitive I2 (left) and P-cells (right). Responses to notch noise $(\mathbf{A}, \mathbf{C})$ and noise band sweeps $(\mathbf{B}, \mathbf{D})$ are shown for different notch or band widths and for different W-cell output bandwidths (wide vs. narrow; 2.2 vs. 0.1 octaves). Responses of the I2-cell (P-cell) are plotted versus the falling (rising) edge frequency of the notch or band. The top plot in each column shows the stimulus spectrum at the peak discharge rate for the $1 / 2$ octave notch or band. In general, decreasing the output bandwidth of the W-cells increases the peak rate of model DCN cells. Note that W-cells with narrow output bandwidths are unable to inhibit Pcells for wide notches centered on unit BF (C, arrow).

in response rate below $\mathrm{BF}$. This is because the features exhibited in P-cell maps are shaped primarily by strong inhibitory inputs from the I2-cells: when the maps of the I2-cells shifted to lower frequencies with increasing sound levels, the CIA in the P-cell map shifted to lower frequencies.

The corresponding BF-tone rate-level curves for these I2- and P-cells are shown as the thin lines in Figs. $8 \mathrm{~B}$ and $\mathrm{D}$, respectively. In the wideband case, the responses of the I2-cell (solid line; Fig. 8B) climbed rapidly to a maximum and then declined slowly with level. By contrast, the rate-level function of the P-cell was highly nonmonotonic (solid line; Fig. 8D); as level increased, the unit exhibited a rate increase followed by strong inhibition. When the output bandwidth of the $\mathrm{W}$-cells was narrowed, more W-cells were activated by $\mathrm{BF}$ tones. As a result, the rate-level curve of the I2cell (dashed line; Fig. 8B) showed a lower maximum rate and a steeper decline in rates at higher stimulus levels. In turn, the net (W + I2 cell) effect on the P-cell was an increase in its response rate at higher stimulus levels, although the cell was still inhibited (dashed line; Fig. 8D).

The noise rate-level curves for the I2- and P-cells as a function of W-cell output bandwidth are shown as thick lines in Figures 8B and D. Regardless of the Wcell output bandwidth, the I2-cell (Fig. 8B) showed weak excitatory responses to noise, whereas the P-cell (Fig. 8D) showed robust excitatory responses. The output bandwidth of the W-cells had little effect on these curves because noise always activated the entire population of W-cells regardless of how they were connected to the other cell types.

Figure 9 shows the responses of the I2- and P-cells to notch noise and noise band sweeps; responses of the I2-cell are shown in the left column, and responses of the P-cell are shown in the right column. For each plot, different panels (top vs. bottom) indicate different notch or band widths ( 0.5 vs. one octave), and different line types (solid vs. dashed) represent different W-cell output bandwidths (wide vs. narrow). Note that the I2-cell showed strongly 

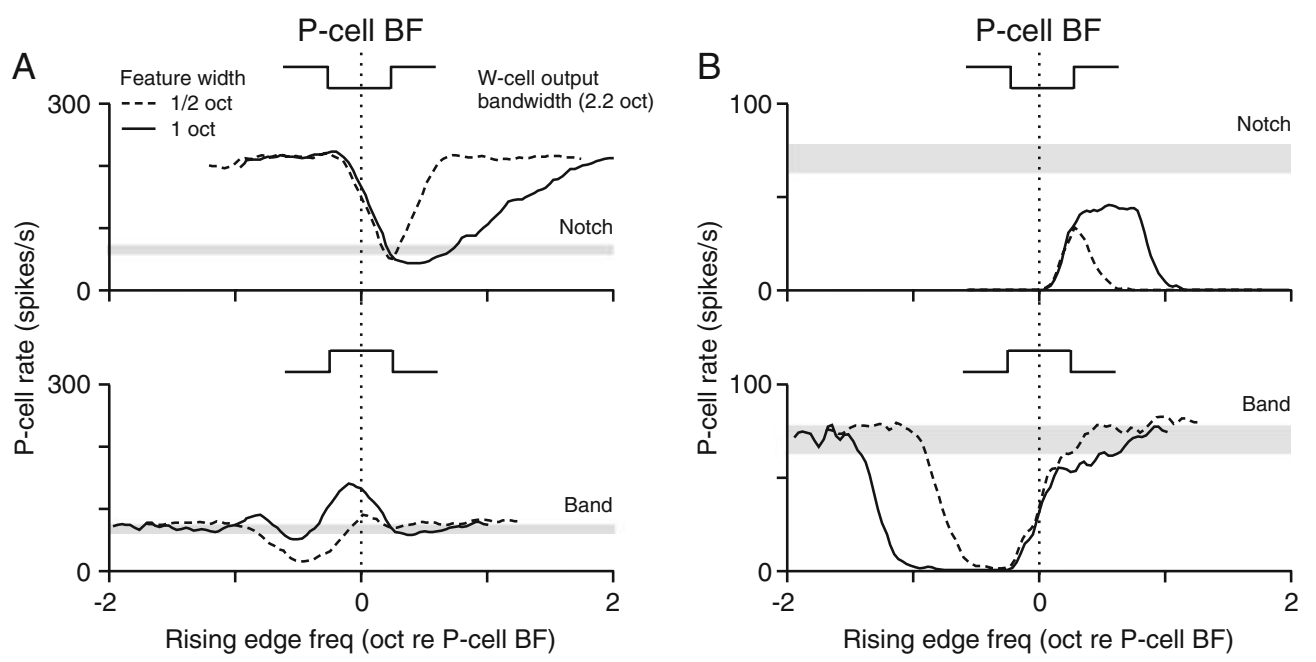

FIG. 10. Responses of non-edge-sensitive P-cells of the notch-inhibited (A) and notch-excited types (B) to notch noise (top) and band noise (bottom) sweeps. Responses are plotted versus the rising edge of the notch or band; insets show the stimulus spectrum at the peak excursions in rate for the 1/2-octave notch or band. Different line types indicate different notch or band widths. Notch-inhibited (excited) units are inhibited (excited) by notches centered on BF and excited (inhibited) by bands at BF.

modulated responses to both notch noise (Fig. 9A) and noise band sweeps (Fig. 9B). For both stimulus types, the cell showed its peak response with the falling spectral edge aligned near BF; the stimulus eliciting the peak response for the 0.5 octave notch or band is shown at the top of the plots. In response to notch sweeps (Fig. 9A), the peak response increased with increasing notch width and decreasing W-cell output bandwidth because both manipulations reduced more selectively the excitatory drive to the above-BF W-cells resulting in greater release from $\mathrm{W}$ cell inhibition. By contrast, the peak response rate to noise bands (Fig. 9B) was less affected (reduced slightly) by noise band width or W-cell output bandwidth because these stimuli activated excitatory AN-fiber inputs to the I2-cell without activating greatly the excitatory inputs to the inhibitory W-cells.

The responses of the P-cell differed from those of the I2-cell in that peak responses were not seen at falling spectral edges, but rather when rising spectral edges aligned near BF (Figs. 9C and D); again, the stimulus eliciting the maximum rate is shown at the top of each plot. For both notch noise and noise band sweeps, the peak rate occurred when the P-cell received its strongest excitatory AN-fiber input opposed by its weakest inhibitory I2-cell input (recall that the center of I2-cell inputs to a P-cell is offset -0.1 octaves relative to the $\mathrm{BF}$ of the $\mathrm{AN}$-fiber inputs). In response to notch sweeps (Fig. 9C), the peak response changed little with increasing notch width because the 0.5-octave-wide notch was sufficient already to reduce almost to zero the excitatory drive to the I2-cells. The effects of decreasing W-cell output bandwidth were twofold: to increase the peak rate (and response rates for other rising edge frequencies remote to $\mathrm{BF}$ ) and to eliminate the inhibitory response for edge frequencies just above BF when the notch was wide (arrow). The former effect was due to the indirect effects of $\mathrm{W}$ cells decreasing the response of I2-cells (Fig. 9A), whereas the latter effect resulted from W-cells with narrow output bandwidths being unable to inhibit Pcells for wide notches centered on unit BF. For narrow notches, the W-cell output bandwidth has little effect on edge frequencies just above BF because inhibition from both I2- and W-cells contributes to this inhibitory response. In response to band sweeps (Fig. 9D), the peak rate of the P-cell increased with increasing band width and decreasing W-cell output bandwidth because of the indirect effects of W-cells reducing slightly the activity of I2-cells (Fig. 9B; even small changes in I2-cell activity can have large effects on Pcell activity).

The results in Figs. 8 and 9 replicate well the known physiology of edge-sensitive type II and type IV units, particularly when the output bandwidth of the $\mathrm{W}$-cells is wide. Thus, these results demonstrate that the two-inhibitor model of the DCN, when the W-cells are in NIWO form, is capable of simulating qualitatively the responses of typical DCN cells to sound. To explore further the capabilities of the model with NIWO W-cells, the model was modified in ways consistent with those suggested by Reiss and Young (2005) to test whether it could also account for the responses of their non-edge-sensitive type IV units. Non-edge-sensitive units have been grouped into two main types: notch inhibited units are inhibited by notch noise centered on BF; and notch excited units are excited by notches centered on BF.

Figure $10 \mathrm{~A}$ and $\mathrm{B}$ shows the responses of notchinhibited and notch-excited P-cells, respectively, to 
notch-noise and noise band sweeps. In these simulations, the center of the I2-P cell connection was shifted to 0 octaves to eliminate the release from I2cell inhibition that causes the rate peak in edgesensitive P-cells. The notch-inhibited P-cell was then created by increasing the W-I2 cell connection strength by a factor of two (to reduce selectively I2cell responses to wideband stimuli), whereas the notch-excited P-cell was created by decreasing the WI2 connection strength by a factor of seven (to eliminate in effect W-cells from the circuit). Note that with essentially only its weak W-cell inputs responding to wideband stimuli, the response of the notchinhibited P-cell (Fig. 10A) resembled nearly that of its AN-fiber inputs; that is, it was inhibited by notches centered at $\mathrm{BF}$ and excited by bands at $\mathrm{BF}$ (the stimulus eliciting these responses for the 0.5 octave notch or band is shown at the top of the plots). By contrast, the notch-excited unit (Fig. 10B) was excited by notches and inhibited by bands centered at $\mathrm{BF}$ where the cumulative response of its very strong I2cell inputs (which resembled that of its own AN-fiber input) was either zero or at a maximum. With the exception of an inadvertent mislabeling issue (Reiss and Young Fig. 7D; labeled rising rather than falling edge; personal communication), the responses of these model types including responses to tones and noise (not shown) match qualitatively those of the corresponding type IV unit response types. Whether the model can produce quantitative fits to the full range of responses of an individual edge or non-edgesensitive unit awaits further study.

\section{DISCUSSION}

Physiological and behavioral studies in cats have established that type IV units in the DCN initiate a functionally segregated pathway in the auditory system that is specialized to process spectral cues to the location of sounds in space (Spirou and Young 1991; Young et al. 1992; Nelken and Young 1994; May 2000; Davis 2002; Reiss and Young 2005). Early physiological and modeling studies suggested that type IV unit sensitivity to spectral notches was shaped largely by inhibitory inputs from WBIs (Nelken and Young 1994; Hancock and Voigt 1999), whereas recent findings have called into question a central role for the WBIs (Reiss and Young 2005). In particular, it was found that W-cells with relatively tightly bandlimited inputs and outputs (NINO form) were unable to inhibit Pcells in response to notch-noise stimuli with wide notches (Reiss and Young 2005; Fig. 5). The results here demonstrate that WBIs in narrow-input wideoutput (NIWO) form are capable of explaining fully the notch sensitivity of type IV units without adversely affecting the responses of model cells to other basic stimuli.

In the NIWO form of the conceptual model, the restriction on the bandwidth of $\mathrm{W}-\mathrm{P}$ cell projections was removed so that P-cells received inputs from $\mathrm{W}$ cells over a frequency range up to three octaves wide. This is consistent with anatomical studies suggesting that single onset-C units (or D-stellate cells or radiate neurons), the neural correlates of the WBI, innervate at least one third of the mediolateral aspect (tonotopic axis) of the DCN (Oertel et al. 1990; Doucet and Ryugo 1997; Arnott et al. 2004). Given the frequency organization of the DCN (Spirou et al. 1993), this corresponds to a minimum WBI projection bandwidth of about one-two octaves over the mid-frequency range $(5-18 \mathrm{kHz})$ where spectral notches occur (Musicant et al. 1990; Rice et al. 1992). Each of the $\mathrm{W}$-cells in this set of simulations received AN-fiber inputs over an effective bandwidth of 0.83 octaves and showed $100 \%$ rate modulation to one-octave-wide notch noise sweeps (Fig. 3B). The cumulative W-cell input to P-cells, however, became progressively less sensitive to the loss of excitatory drive at any given notch center frequency as the bandwidth of the $\mathrm{W}-\mathrm{P}$ cell connection increased. In turn, W-cells were able to inhibit progressively more strongly P-cells in response to one-octave wide notch-noise stimuli centered at $\mathrm{BF}$ as a function of increasing $\mathrm{W}-\mathrm{P}$ cell connection bandwidth and strength (Fig. 6). Clearly, if the stimulus had been suprathreshold for any $\mathrm{W}$ cell, a condition likely to be true in vivo, then the cumulative W-cell inhibitory effects on P-cells would be even stronger at any given output bandwidth.

The effects of increasing the bandwidth of the $\mathrm{W}-\mathrm{P}$ cell connection on P-cell responses to notch-noise stimuli have not been explored in previous modeling studies. In the study of Hancock and Voigt (1999), the bandwidth of the $\mathrm{W}-\mathrm{P}$ cell connection was fixed at 0.1 octaves. It was not necessary to alter this parameter to fit type IV unit notch noise data because the W-cells received AN-fiber inputs over a sufficiently wide frequency range $(\geq 1.75$ octaves) so as not to show $100 \%$ rate modulation for wide notches (WINO model). Reiss and Young (2005) also limited the W$\mathrm{P}$ bandwidth to 0.1 octaves. Although this restriction eventually led to problems simulating type IV unit responses to notches, it was likely motivated, in part, by parsimony. That is, it was found that to reproduce most directly the asymmetric response of type II units to notch-noise stimuli required a strong WBI rate modulation and an assumed +0.3 octave offset of the $\mathrm{BF}$ of the W-cell inputs relative to that of the I2-cell. Given that it would be unlikely for onset-C units to make tonotopic projections to type II units but contact near by type IV units over a wide frequency range, the $\mathrm{W}-\mathrm{P}$ cell bandwidth was also constrained. 
The results in this study show that increasing the bandwidth of the W-I2 projection does not change the basic asymmetry of the I2-cell response to notch-noise stimuli (Fig. 4C) because the cumulative W-cell response retains some rate modulation even at the widest bandwidths tested, and the center frequency of the cumulative $\mathrm{W}$-cell activity remains above $\mathrm{BF}$ (as long as the bandwidth expansion is symmetric).

The NIWO model, which accurately reproduces WBI unit sensitivity to notches, is very similar to the original WINO model of Hancock and Voigt (1999) in its ability to account for type IV unit responses to stimuli with sharp spectral features like notches and peaks. Although the NIWO model was not fit (least squares) to type IV unit notch widening data, the plots of discharge rate as a function of notch edge frequency show that the results from the two models overlap one another in addition to overlapping the experimental data (WINO: Fig 1B; NIWO: Fig. 7). The presence of wideband inhibition in both models also qualitatively accounts for some type IV response frequency map properties, including a weak upper excitatory region and the emergence of an upper inhibitory sideband (Fig. 8C; Hancock and Voigt 1999; Reed and Blum 1997). These results are perhaps not surprising given that the two models can be thought of as logically equivalent. In the WINO model, P-cells are inhibited by W-cells which sum auditory nerve input over a wide frequency range and thus are relatively insensitive to sharp spectral features. In the NIWO model, individual W-cells are sensitive to notches or peaks at their own BF, but P-cells are inhibited by the summed activity of $\mathrm{W}$-cells across frequency, and this summed activity is insensitive to sharp spectral features.

The results of the present modeling study suggest that WBIs, in NIWO form, are capable of accounting fully for the notch sensitivity of type IV units. In this study, all of the W-cells had an effective auditory nerve integration bandwidth of 0.83 octaves, and the $\mathrm{W}-\mathrm{P}$ cell projections were either uniform or Gaussian distributed. With regard to the integration bandwidth, the narrow effective input range of the W-cells is consistent with prior physiological studies showing that onset-C units receive a heavy frequency weighting for stimuli in the region of unit BF (Jiang et al. 1996; Palmer et al. 1996; Reiss and Young 2005). However, it should be noted that not all (one out of two) onset-C units show $100 \%$ modulation to one-octave-wide notch sweeps suggesting that the effective bandwidth of auditory nerve input to some onset-C units is greater than 0.83 octaves (Reiss and Young 2005; Fig. 1C). It is known that W-cells with wider integration bandwidths are capable of shaping P-cell notch sensitivity (Hancock and Voigt 1999). With regard to the $\mathrm{W}-\mathrm{P}$ cell projection, it is known that the axons of
onset-C units ramify widely in the DCN (Oertel et al. 1990; Doucet and Ryugo 1997; Arnott et al. 2004), but the pattern of effective WBI input to type IV units is unknown. As more detailed information about the projections to and from WBI units becomes known, refining both the conceptual and computational models of the DCN will be possible.

\section{ACKNOWLEDGMENTS}

This work was supported by National Institute of Deafness and Other Communication Disorders grant DC05161. We thank Nathanial Greene for helpful comments on the manuscript.

\section{REFERENCES}

ADAms JC. Ascending projections to the inferior colliculus. J. Comp. Neurol. 183:519-538, 1979

Arnott RH, Wallace MN, Shackleton TM, Palmer AR. Onset neurones in the anteroventral cochlear nucleus project to the dorsal cochlear nucleus. J. Assoc. Res. Otolaryngol. 5:153-170, 2004.

Bruce IC, Sachs MB, Young ED. An auditory-periphery model of the effects of acoustic trauma on auditory nerve responses. J. Acoust. Soc. Am. 113:369-388, 2003.

CARNEY LH. A model for the responses of low-frequency auditorynerve fibers in cat. J. Acoust. Soc. Am. 93:401-417, 1993.

DAvIS KA. Evidence of a functionally segregated pathway from dorsal cochlear nucleus to inferior colliculus. J. Neurophysiol. 87:1824$1835,2002$.

Doucet JR, Ryugo DK. Projections from the ventral cochlear nucleus to the dorsal cochlear nucleus in rats. J. Comp. Neurol. 385:245264, 1997.

Hancock KE, Voigt HF. Wideband inhibition of dorsal cochlear nucleus type IV units in cat: a computational model. Ann. Biomed. Eng. 27:73-87, 1999.

Hancock KE, Voigt HF. Intracellularly labeled fusiform cells in dorsal cochlear nucleus of the gerbil. II. Comparison of physiology and anatomy. J. Neurophysiol. 87:2520-2530, 2002.

Imig TJ, Bibikov NG, Poirier P, SAmson FK. Directionality derived from pinna-cue spectral notches in cat dorsal cochlear nucleus. J. Neurophysiol. 83:907-925, 2000.

Jiang D, Palmer AR, Winter IM. Frequency extent of two-tone facilitation in onset units in the ventral cochlear nucleus. J. Neurophysiol. 75:380-395, 1996.

Koerber KC, Pfeiffer RR, Warr WB, Kiang NY. Spontaneous spike discharges from single units in the cochlear nucleus after destruction of the cochlea. Exp. Neurol. 16:119-130, 1966.

MacGregor RJ. Neural and brain modeling. Calif, Academic Press, San Diego, 1987.

Manis PB. Membrane properties and discharge characteristics of guinea pig dorsal cochlear nucleus neurons studied in vitro. J. Neurosci. 10:2338-2351, 1990.

MAY BJ. Role of the dorsal cochlear nucleus in the sound localization behavior of cats. Hear. Res. 148:74-87, 2000.

Musicant AD, Chan JC, Hind JE. Direction-dependent spectral properties of cat external ear: new data and cross-species comparisons. J. Acoust. Soc. Am. 87:757-781, 1990.

NelKen I, Young ED. Two separate inhibitory mechanisms shape the responses of dorsal cochlear nucleus type IV units to narrowband and wideband stimuli. J. Neurophysiol. 71:2446-2462, 1994. 
Oertel D, Wu SH, Garb MW, Dizack C. Morphology and physiology of cells in slice preparations of the posteroventral cochlear nucleus of mice. J. Comp. Neurol. 295:136-154, 1990.

Osen KK. Course and termination of the primary afferents in the cochlear nuclei of the cat. An experimental anatomical study. Arch. Ital. Biol. 108:21-51, 1970.

Osen KK. Projection of the cochlear nuclei on the inferior colliculus in the cat. J. Comp. Neurol. 144:355-372, 1972.

Palmer AR, Jiang D, Marshall DH. Responses of ventral cochlear nucleus onset and chopper units as a function of signal bandwidth. J. Neurophysiol. 75:780-794, 1996.

ReEd MC, BLum JJ. Model calculations of the effects of wide-band inhibitors in the dorsal cochlear nucleus. JASA 102:2238-2244, 1997.

ReIss LA, Young ED. Spectral edge sensitivity in neural circuits of the dorsal cochlear nucleus. J. Neurosci. 25:3680-3691, 2005.

Rice JJ, May BJ, Spirou GA, Young ED. Pinna-based spectral cues for sound localization in cat. Hear. Res. 58:132-152, 1992.

Ryugo DK, MAY SK. The projections of intracellularly labeled auditory nerve fibers to the dorsal cochlear nucleus of cats. J. Comp. Neurol. 329:20-35, 1993.

SPIRou GA, Young ED. Organization of dorsal cochlear nucleus type IV unit response maps and their relationship to activation by bandlimited noise. J. Neurophysiol. 66:1750-1768, 1991.

Spirou GA, May BJ, Wright DD, Ryugo DK. Frequency organization of the dorsal cochlear nucleus in cats. J. Comp. Neurol. 329:3652, 1993.
Sutherland DP, Glendenning KK, Masterton RB. Role of acoustic striae in hearing: discrimination of sound-source elevation. Hear. Res. 120:86-108, 1998.

Voigt HF, Young ED. Cross-correlation analysis of inhibitory interactions in dorsal cochlear nucleus. J. Neurophysiol. 64: 1590-1610, 1990

Winter IM, PALMER AR. Level dependence of cochlear nucleus onset unit responses and facilitation by second tones or broadband noise. J. Neurophysiol. 73:141-159, 1995.

Young ED. Identification of response properties of ascending axons from dorsal cochlear nucleus. Brain. Res. 200:23-37, 1980.

Young ED, BrownelL WE. Responses to tones and noise of single cells in dorsal cochlear nucleus of unanesthetized cats. J. Neurophysiol. 39:282-300, 1976

Young ED, VoIGT HF. Response properties of type II and type III units in dorsal cochlear nucleus. Hear. Res. 6:153-169, 1982.

Young ED, Spirou GA, Rice JJ, Voigt HF. Neural organization and responses to complex stimuli in the dorsal cochlear nucleus. Philos. Trans. R. Soc. Lond. B. Biol. Sci. 336:407413, 1992.

Zhang X, Heinz MG, Bruce IC, Carney LH. A phenomenological model for the responses of auditory-nerve fibers: I. Nonlinear tuning with compression and suppression. J. Acoust. Soc. Am. 109:648-670, 2001.

ZILANY MS, BRUCE IC. Modeling auditory-nerve responses for high sound pressure levels in the normal and impaired auditory periphery. J. Acoust. Soc. Am. 120:1446-1466, 2006. 